\title{
Vitamin D deficiency in white, apparently healthy, free-living adults in a temperate region
}

\author{
Panagiotis N. Singhellakis, ${ }^{1}$ Fotini Ch. Malandrinou, ${ }^{1}$ Catherine J. Psarrou, ${ }^{1}$ \\ Alexandra M. Danelli, ${ }^{1}$ Sotirios D. Tsalavoutas, ${ }^{2}$ Evangelia S. Constandellou ${ }^{2}$ \\ ${ }^{1}$ Department of Endocrinology, Metabolism and Diabetes Mellitus "Saint Savvas" Cancer Hospital, Athens, ${ }^{2}$ Hormonal \\ Laboratory, "Agios Panteleimon" General Hospital of Nikaia, Piraeus, Greece
}

\begin{abstract}
OBJECTIVE: The precise incidence of vitamin $D$ deficiency is not known, primarily because there is no consensus on the optimal levels of serum $25(\mathrm{OH})$ Vitamin D. The aim of the present study was to determine the incidence of vitamin $D$ deficiency in a large group of normal adult volunteers residing in a typical temperate region. DESIGN-METHODS: In 625 healthy, free living adults (553 women, 72 men, aged 18-85 years), serum 25(OH)Vitamin $D$ and 1-25(OH) $)_{2}$ Vitamin D (RIA), plasma intact PTH (ECLIA) and routine chemistries (multianalyser) were determined at baseline once during a whole year. In a subgroup of 36 subjects, a vitamin $D$ loading (suppression) test was also performed to define the lower normal values for these two Vitamin D metabolites. RESULTS: The estimated lower normal values, based on the results of the vitamin $D_{2}$ loading test, were $22 \mathrm{ng} / \mathrm{ml}(55 \mathrm{nmol} / \mathrm{L})$ for $25(\mathrm{OH})$ Vitamin $D$ and $24.6 \mathrm{pg} / \mathrm{ml}$ $(59 \mathrm{pmol} / \mathrm{l})$ for $1-25(\mathrm{OH})_{2}$ Vitamin $D$. During the whole year, the incidence of low values was $57.7 \%$ for $25(\mathrm{OH})$ Vitamin $D$ and $33.2 \%$ for $1-25(\mathrm{OH})_{2}$ Vitamin $D$. A highly significant $(p<0.001)$ positive linear correlation of serum $25(\mathrm{OH})$ Vitamin $D$ with $1-25(\mathrm{OH})_{2}$ Vitamin $D$ values and a negative correlation of $25(\mathrm{OH})$ Vitamin $D$ with intact PTH was observed in the entire group and separately in women without or with osteoporosis and osteopenia. CONCLUSION: Most of the white normal adults living in a temperate region were vitamin $D$ deficient. The observed correlations between serum concentrations of $25(\mathrm{OH})$ Vitamin $D$ and 1-25 $(\mathrm{OH})_{2}$ Vitamin $D$ as well as of $25(\mathrm{OH})$ Vitamin $D$ and intact PTH, suggest that $25(\mathrm{OH})$ Vitamin $D$ is implicated not only in 1-25 $(\mathrm{OH})_{2}$ Vitamin D production but also in PTH secretion.
\end{abstract}

Key words: Intact PTH, Temperate region, Vitamin D deficiency, Vitamin D loading (suppression) test, $1-25(\mathrm{OH})_{2}$ Vitamin $\mathrm{D}, 25(\mathrm{OH})$ Vitamin D

Address for correspondence:

Panagiotis Singhellakis, MD, PhD, "Saint Savvas" Cancer Hospital, 171 Alexandras Ave., GR 115 22, Athens, Greece, Tel: +302106409389, +302106409301, Fax: +302106430915, e-mail: p.singhellakis@gmail.com

Received 08-09-10, Revised 10-12-10, Accepted 20-01-11

\section{INTRODUCTION}

Although vitamin $\mathrm{D}$ deficiency, defined by the serum concentrations of $25(\mathrm{OH})$ Vitamin $\mathrm{D}$ is generally reported as being very common worldwide, ${ }^{1-5}$ its precise incidence, in adults is controversial. ${ }^{1,2,6,7}$ 
This discrepancy is attributed mainly to the absence of consensus on the optimal levels of serum $25(\mathrm{OH})$ Vitamin D. ${ }^{1,2,4,6,7}$ It should be emphasized that what has been considered until recently as the "normal" level of 25(OH)Vitamin D has been mainly defined by measurements in groups of healthy volunteers who, however, include an unknown number of vitamin D insufficient subjects manifesting no clinical symptoms or signs. Consequently, the calculated normal values of $25(\mathrm{OH})$ Vitamin D concentration most likely do not represent the exact normal values. ${ }^{1,3,6}$ The currently used lower normal cut-off values are very low indeed. Certainly, it is very difficult to identify among apparently normal subjects those who are vitamin D sufficient or insufficient. It is thus evident that if vitamin $\mathrm{D}$ insufficiency is defined by the serum concentration of $25(\mathrm{OH})$ Vitamin D below which plasma PTH starts to rise, ${ }^{1-7}$ the lower normal levels could be determined by using a vitamin loading test and examine the changes of serum $25(\mathrm{OH})$ Vitamin $\mathrm{D}$ and plasma PTH concentrations during the procedure..$^{1-7}$ Then the level of serum 25(OH)Vitamin D at which plasma PTH concentrations begin to form a virtual plateau is taken as the lower normal limit. ${ }^{1-7}$

To our knowledge, a vitamin D loading (suppression) test has been reported once by Malabanan et $\mathrm{al} ;{ }^{7}$ they estimated that serum $25(\mathrm{OH})$ Vitamin D of $20 \mathrm{ng} / \mathrm{ml}(50 \mathrm{nmol} / \mathrm{L})$ represents the lower normal level. Other investigators examined the changes of plasma PTH concentrations in relation to those of serum $25(\mathrm{OH})$ Vitamin $\mathrm{D}$ in healthy adults at baseline, to the point at which the plasma PTH concentrations formed a plateau (if this occured). The serum $25(\mathrm{OH})$ Vitamin D values corresponding at the point of PTH plateau was taken as the lower normal value of $25(\mathrm{OH})$ Vitamin D (between 20-40ng/ml, 50-80nmol/L). ${ }^{1-6}$

Heaney et $\mathrm{al}^{8}$ reported that the maximum intestinal calcium absorption (65\%) occurs when the serum $25(\mathrm{OH})$ Vitamin D levels are at least $32 \mathrm{ng} / \mathrm{ml}$ $(80 \mathrm{nmol} / \mathrm{L})$. Since the maximun intestinal calcium absorption is physiologically necessary to maintain a sufficient calcium uptake, irrespective of the daily dietary calcium intake variations, the $32 \mathrm{ng} / \mathrm{ml}$ $(80 \mathrm{nmol} / \mathrm{L})$ serum concentration of $25(\mathrm{OH})$ Vitamin D should be considered as the lower normal level. ${ }^{1-3,8}$ Although there is no agreement on the definition of the lower normal level of serum 25(OH)Vitamin D, most reports place this value between 20 and 40ng/ $\mathrm{ml}(50-80 \mathrm{nmol} / \mathrm{L})$. It must be added that the definition of the lower normal limits of the active vitamin $\mathrm{D}$ metabolite $\left[1-25(\mathrm{OH})_{2}\right.$ Vitamin $\left.\mathrm{D}\right]$ is even more problematic.

Therefore, the present study was undertaken to determine: a) the lower normal levels of serum $25(\mathrm{OH})$ Vitamin D and of 1-25(OH $)_{2}$ Vitamin D concentrations by using a vitamin $\mathrm{D}$ loading test in a group of normal, free living adults. Additionally an effort was made to also define these levels by examining, at baseline, the point at which the plasma PTH concentrations begin to form a plateau and $b$ ) the prevalence of the so-defined vitamin $\mathrm{D}$ deficiency during a whole year in a representative group of white, free living adults residing in a region with a temperate climate (northern latitude $38^{\circ}$ ).

\section{SUBJECTS AND METHODOLOGY}

We studied a total of 625 (553 females, 72 males) white, apparently healthy, free living adult subjects (aged 18-85 yr, mean \pm sd:54.05 \pm 14 , median age 55 yr), residents of Athens and its broad territory, a region inhabited by $35 \%$ of the total population of Greece. Subjects were excluded from the study if during the last six months had used a medication known to affect calcium and vitamin D metabolism, or if, for the last year, they had used other antiresoptive or anabolic treatment for the prevention or treatment of osteoporosis. Other exclusion criteria were the presence of diseases that affected calcium homeostasis, such as metabolic bone diseases other than uncomplicated osteoporosis and other metabolic diseases (untreated diabetes mellitus, hyper- or hypothyroidism).

Osteoporosis was detected in 127 (120 females and 7 males) and osteopenia in 91 (87 females and 4 males) subjects. Measurements were carried out by DEXA (Lunar Co) in the femoral neck or lumbar spine or both. For the diagnosis, the $\mathrm{WHO}^{4}$ criteria were applied (T-score, in at least one side between -1 to -2.5 for osteopenia and $>-2.5$ for osteoporosis. Osteoporosis was slight or moderate (T-score $>-2.5$ to -3.2); osteoporotic fractures were not reported (exclusion criterion). None of the 229 subjects was under treatment, either because the diagnosis was established at the time of the study or because they had 
for various reasons stopped any relevant medications for at least six months (calcium and/or Vitamin D) or 1 year (antiresorptive or anabolic) prior to the study.

Fasting blood samples were obtained randomly (unbalanced design) at baseline from all subjects once during a year (February 2004 - January 2005) for the determinations of serum $25(\mathrm{OH})$ Vitamin D, $1-25(\mathrm{OH})_{2}$ Vitamin D, plasma intact PTH, calcium (total, ionized), phosphorus, magnesium and proteins.

Serum 25(OH)Vitamin D and 1-25(OH $)_{2}$ Vitamin $\mathrm{D}$ were measured by RIA (the latter after purification in human serum by immunoextraction) using kits from IDS Ltd, Tune and Wear, UK. The intraassay coefficient of variation $(\mathrm{CV})$ was $3.4-5.1 \%$, the inter-assay CV 8.9-14.1\% and the sensitivity $<1 \mathrm{ng} /$ $\mathrm{ml}(<2.5 \mathrm{nmol} / \mathrm{L})$ for $25(\mathrm{OH})$ Vitamin D. The interassay CV was $7.6-15.8 \%$ and the sensitivity $<0.3 \mathrm{pg} /$ $\mathrm{ml}(<0.72 \mathrm{pmol} / \mathrm{L})$ for $1-25(\mathrm{OH})_{2}$ Vitamin D. According to the manufacturer the RIA method used for the measurement of 25(OH)Vitamin D equally measures $25(\mathrm{OH})$ Vitamin $\mathrm{D}_{3}$ and $25(\mathrm{OH})$ Vitamin $\mathrm{D}_{2}$. We have, nevertheless, shown (unpublished observations) that Vitamin $\mathrm{D}_{2}$ is measured to a lesser extent (about 10\%). Plasma intact PTH was measured by an Electrochemiluminescence (ECLIA) immunoassay (Nichols Institute, San Juan Calif., USA) with an inter-assay $\mathrm{CV}<5 \%$. Routine chemistries were measured by a Hitachi multichannel analyzer. Serum ionized calcium was measured by an ion-sellective electrode (Bayer 634 analyzer) at physiological pH.

In order to determine the lower normal levels of the vitamin D metabolites [25(OH)Vitamin D and $1-25(\mathrm{OH})_{2}$ Vitamin D], a vitamin D loading test was carried out in 36 of the subjects ( 27 females, 9 males, aged 28-56 yr); $7000 \mathrm{IU}$ vitamin $\mathrm{D}_{2}$ plus $1 \mathrm{~g}$ calcium carbonate were administered per os daily for eight weeks. In these subjects the above mentioned indices were measured both before and at the end of the loading test. All 36 subjects gave informed consent and hospital ethics committee approval was obtained in accordance with the Helsinki Declaration.

It was additionally examined whether or not the lower normal levels of serum $25(\mathrm{OH})$ Vitamin D concentrations could be also estimated by using the regression line between plasma intact $\mathrm{PTH}$ and serum $25(\mathrm{OH})$ Vitamin $\mathrm{D}$ values determined at baseline in the entire group of studied subjects until PTH values reached an almost stable plateau.

\section{STATISTICAL ANALYSIS}

Pairwise correlations between intact PTH and $25(\mathrm{OH})$ Vitamin D, PTH and $1-25(\mathrm{OH})_{2}$ Vitamin D, $25(\mathrm{OH})$ Vitamin D and $1-25(\mathrm{OH})_{2}$ Vitamin D, were assessed via Pearson's correlation coefficient by using the numerical, the semi-log and the log-log values. The correlations between intact PTH and $25(\mathrm{OH})$ Vitamin D were also graphically displayed along with both a linear and LOWESS regression (locally weighted regression scatterplot smoothing curve).

To assess the difference in mean concentrations of each of the two vitamin $\mathrm{D}$ metabolites between the periods of lower and higher values [March-May and July-October for 25(OH)Vitamin D or March-May and August-September for 1-25(OH $)_{2}$ Vitamin D], the two-independent Student t-test was used.

To assess the difference in percentage of adult age groups with low serum $25(\mathrm{OH})$ Vitamin $\mathrm{D}$ and $1-25(\mathrm{OH})_{2}$ Vitamin D concentrations the proportion test was used.

All statistical analyses were carried out in SPSS v.11.5.

\section{RESULTS}

The pre-treatment $25(\mathrm{OH})$ Vitamin D serum values in the 36 subjects undergoing the loading test ranged from $8-34.7(20-86.7 \mathrm{nmol} / \mathrm{L})$. Prior to the vitamin D loading test, 3 cut-offs percentage of intact PTH decrease were considered: a $>40 \%$ decrease (high suppression), a 10 to $40 \%$ decrease (moderate to low suppression, and a $<10 \%$ decrease (no suppression). Specifically, by using the above cut-offs, three subgroups were identified (Figure 1): Group I $(\mathrm{n}=10)$ with a highly significant $(\mathrm{p}<0.001)$ decrease of plasma intact PTH $(\sim 49.4 \%)$ and basal serum 25(OH)Vitamin D values between 8-15ng/ $\mathrm{ml}(20-37.5 \mathrm{nmol} / \mathrm{L})$, group II $(\mathrm{n}=14)$ with a highly significant $(\mathrm{p}<0.001)$ decrease of intact PTH but to a lesser degree $(\sim 34.7 \%)$ and corresponding basal $25(\mathrm{OH})$ Vitamin D values between $15.1-21.8 \mathrm{ng} / \mathrm{ml}$ $(37.7-54.5 \mathrm{nmol} / \mathrm{L})$, and group III $(\mathrm{n}=12)$ without any significant $(\mathrm{p}=0.246)$ decrease $(-1.9 \%)$ of intact 
VITAMIN D LOADING TEST

(7000 IU Vitamin D2 and 1000mg calcium carbonate given per os daily for 8 weeks)

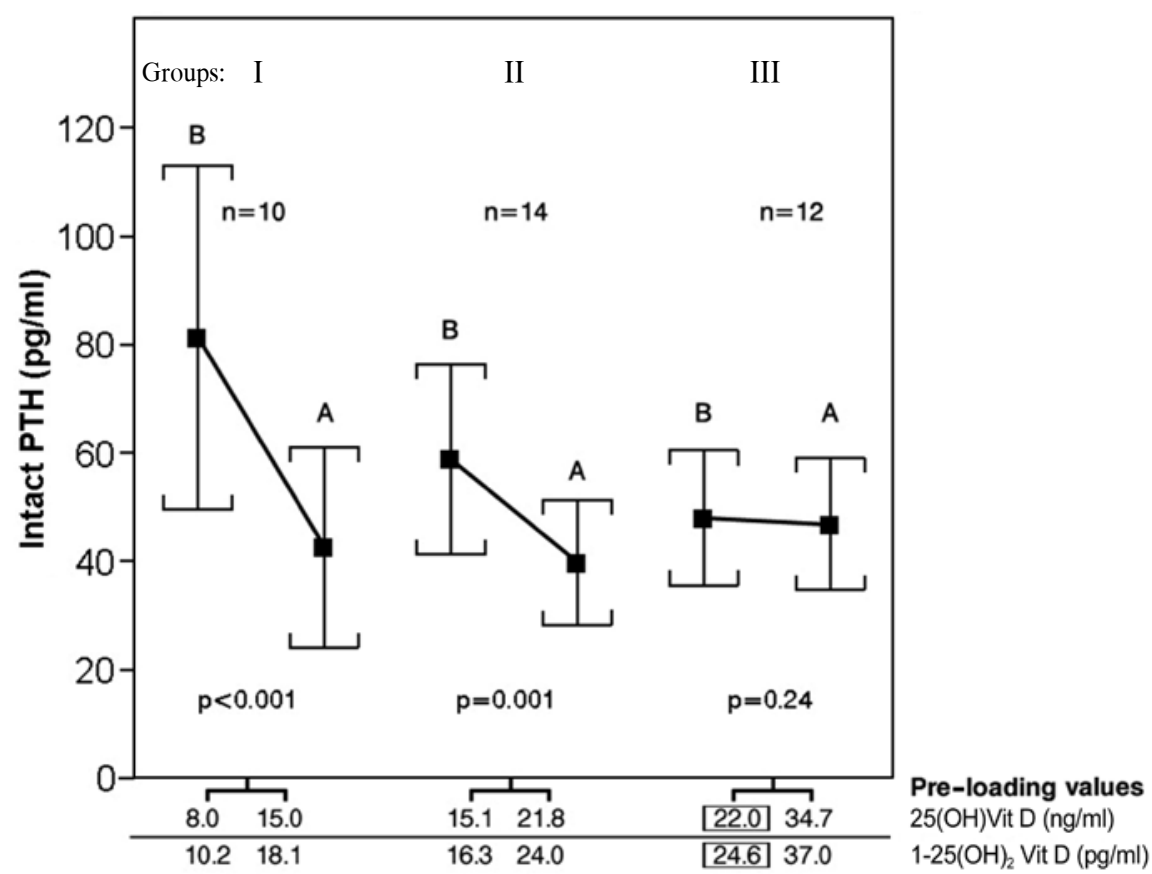

Figure 1. Plasma intact PTH values before $(B)$ and at the end $(A)$ of the test. Highly significant $(\mathrm{p}<0.001)$ suppression of the intact PTH plasma values in the subgroups I and II (-49.4\% and $-34.7 \%$, respectively) compared to preloading serum $25(\mathrm{OH})$ Vitamin values (8-15 and 15.1-21.8ng/ml, respectively) were observed. No suppression of plasma intact PTH values (mean -1.9\%) in subgroup III was noted. The lower preloading value of serum $25(\mathrm{OH})$ Vitamin D $(22 \mathrm{ng} / \mathrm{ml})$ and the corresponding value of $1-25(\mathrm{OH})_{2} \mathrm{Vitamin} \mathrm{D}$ $(24.6 \mathrm{pg} / \mathrm{ml})$ in Group III were considered as the lower normal levels, respectively.

To convert to SI units, multiply by 0.105 for intact PTH, by 2.5 for $25(\mathrm{OH})$ Vitamin D and by 2.4 for $1-25(\mathrm{OH})_{2}$ Vitamin D.

PTH and basal 25(OH)Vitamin D values between $22-34.70 \mathrm{ng} / \mathrm{ml}$ (55-86.75nmol/L) (Figure 1).

The degree of PTH suppression was related to the basal serum 25(OH)Vitamin D values. Therefore, the subjects of the first two subgroups [basal serum $25(\mathrm{OH})$ Vitamin D values $<22 \mathrm{ng} / \mathrm{ml}(<55 \mathrm{nmol} / \mathrm{L})]$ should be considered as vitamin D deficient, while those of the third subgroup [basal 25(OH)Vitamin $D$ values $\geq 22 \mathrm{ng} / \mathrm{ml}$ or $55 \mathrm{nmol} / \mathrm{L}]$ as vitamin D sufficient. Consequently, the lower 25(OH)Vitamin D value obtained in subgroup III $(22 \mathrm{ng} / \mathrm{ml}, 55 \mathrm{nmol} / \mathrm{L})$ would be considered as the lower normal value for this metabolite for our laboratory and the methods used. Moreover, the concomitant lower serum $1-25(\mathrm{OH})_{2}$ Vitamin $\mathrm{D}$ value of the third subgroup $(24.6 \mathrm{pg} / \mathrm{ml}, 59 \mathrm{pmol} / \mathrm{L})$ could be also considered as the lower normal value for this vitamin D metabolite.

An attempt was also made to determine the lower normal serum concentrations of $25(\mathrm{OH})$ Vitamin D, by using the correlation line between plasma intact PTH and serum 25(OH)Vitamin D concentrations. Between plasma intact PTH concentrations and those of serum $25(\mathrm{OH})$ Vitamin $\mathrm{D}$, a highly significant negative linear correlation $(\mathrm{r}=-0.29, \mathrm{p}<0.001)$ was observed without the formation of any plateau (Figure 2a). This correlation did not change if the semi-log or the log-log values were applied (data not shown in graphics). However, when the locally weighed regression scatterplot smoothing (LOWESS) plot was used (Figure 2b), a virtual plateau of the regression line began to appear at serum concentrations of $25(\mathrm{OH})$ Vitamin D between $22-32 \mathrm{ng} / \mathrm{ml}(55-80 \mathrm{nmol} / \mathrm{L})$, a finding suggesting that the point at which the plateau of the line starts could be considered as the lower normal value for the $25(\mathrm{OH})$ Vitamin $\mathrm{D}(22 \mathrm{ng} / \mathrm{ml}, 55 \mathrm{nmol} / \mathrm{L})$. Therefore, by both methods used (vitamin D loading test or the point at which PTH values reaches a virtual 

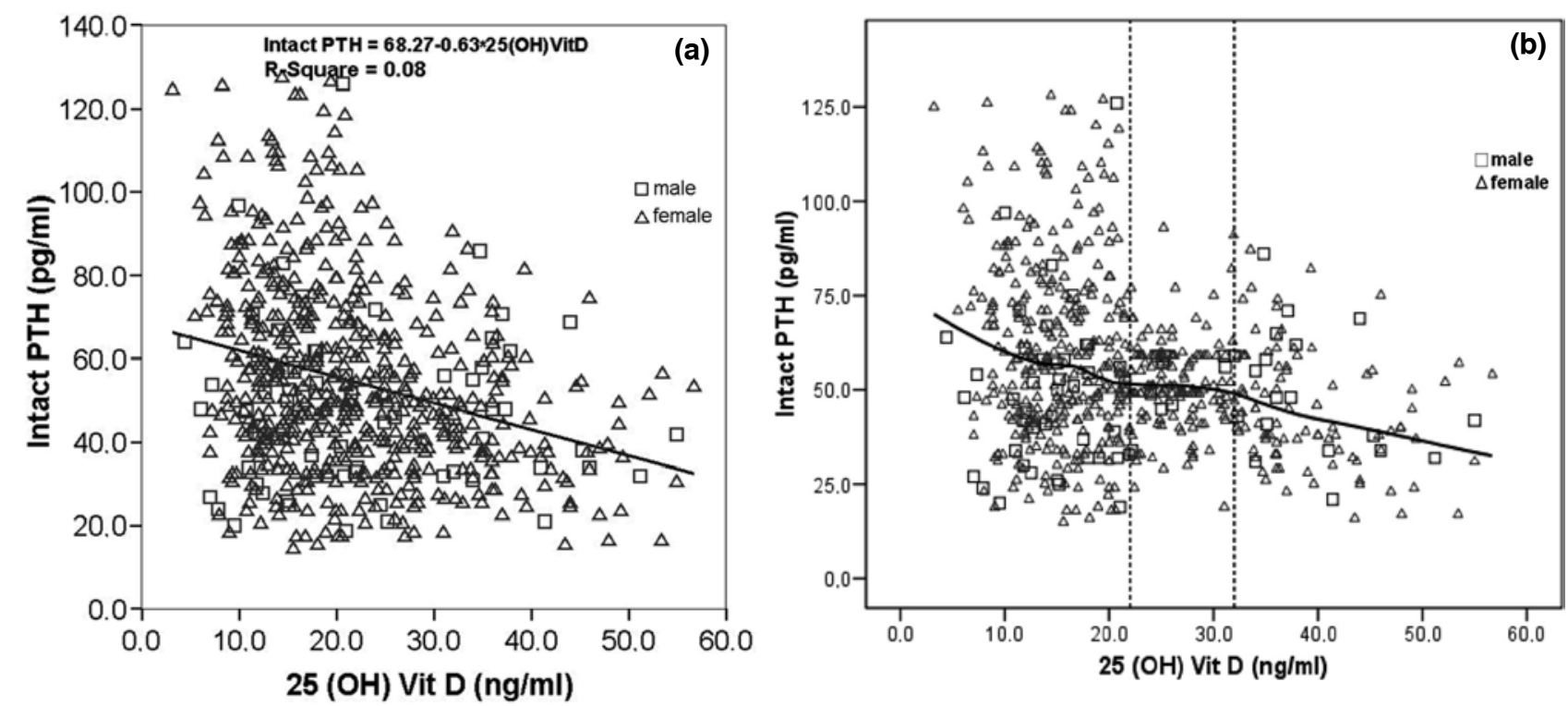

Figure 2. Highly significant negative linear correlation $(r=-0.29 \mathrm{p}<0.001)$ between serum intact PTH and 25(OH)Vitamin D concentrations (a). The LOWESS plot (b) indicates a virtual plateau of the line between the 22-32ng/ml of serum 25(OH)Vitamin D (perpendicular lines), suggesting that the $22 \mathrm{ng} / \mathrm{ml}$ could be considered as the lower normal level for $25(\mathrm{OH}) \mathrm{Vitamin} \mathrm{D}$.

To convert to SI units multiply by 0.105 for intact PTH and by 2.5 for $25(\mathrm{OH})$ Vitamin D.

plateau in the regression line between basal plasma intact PTH and serum 25(OH)Vitamin D concentrations), the lower normal level of serum $25(\mathrm{OH})$ Vitamin D was comparable ( $\geq 22 \mathrm{ng} / \mathrm{ml}, 55 \mathrm{nmol} / \mathrm{L})$. It should be emphasized, however, that with the second approach the estimation was less clear even by using the LOWESS plot alone.

In Figure 3 the distribution of serum $25(\mathrm{OH})$ Vitamin $\mathrm{D}$ values is shown for each month. Values below the lower normal level ( $<22 \mathrm{ng} / \mathrm{ml}, 55 \mathrm{nmol} / \mathrm{L})$, defined by the loading test, were observed in $361 / 625$ subjects $(57.7 \%)$ over the entire year.

The values of $1-25(\mathrm{OH})_{2}$ Vitamin $\mathrm{D}$ for each month are shown in Figure 4. Values below the lower normal level $(24.6 \mathrm{pg} / \mathrm{ml}, 59 \mathrm{pmol} / \mathrm{L})$, defined by the loading test, were observed in 209/625 subjects (33.3\%). The wide range of values of the two vitamin D metabolites is demonstrated in Figures 3 and 4. The lower mean values were observed during March-May for both Vitamin D metabolites, whereas 25(OH)Vitamin D was higher during July-October and 1-25(OH $)_{2}$ Vitamin $\mathrm{D}$ during August-September. It should be underlined that low values of $25(\mathrm{OH})$ Vitamin D $(<22 \mathrm{ng} / \mathrm{ml}$, $55 \mathrm{nmol} / \mathrm{L}$ ) were observed in most of the studied subjects $(77.2 \%)$ at the lower values period (March-May) but only in $35.6 \%$ at the higher values period (JulyOctober). Furthermore the low 1-25(OH $)_{2}$ Vitamin D values were observed in $35.1 \%$ of the subjects in the period March-May and in $9.9 \%$ at the higher values period (August-September).

It was also examined whether the percentage of abnormally low values of both the vitamin $\mathrm{D}$ metabolites in the studied adults was influenced by age during the year. The studied subjects were therefore stratified into five age groups $(<29,30-39,40-49$, $50-59,>60 \mathrm{yr})$ of either gender.

The percentage of low 25(OH)Vitamin D values $(<22 \mathrm{ng} / \mathrm{ml}, 55 \mathrm{nmol} / \mathrm{L})$ during the period March-May (Figure 5) was very high in all age groups ranging from $60.4 \%$ (age group 50-59, $\mathrm{n}=53$ ) to $100 \%$ (age groups $<29, \mathrm{n}=14,30-39 \mathrm{yr}, \mathrm{n}=13$ ), with significant difference between the age groups of $<29(100 \%)$, $30-39(100 \%)$ and $40-49, \mathrm{n}=24(87.5 \%)$ compared to the age group 50-59 (60.4\%) $(\mathrm{p}=0.004,0.05,0.02$, respectively) and between the age groups of $>60$, $\mathrm{n}=67(77.6 \%)$ and $50-59(\mathrm{p}=0.05)$. The corresponding percentages in the period of higher values (JulyOctober) were significantly lower, than those in the previous period, ranging between $24.5-33.3 \%$ in all age groups except the group $>60, n=60(51.7 \%)$. 


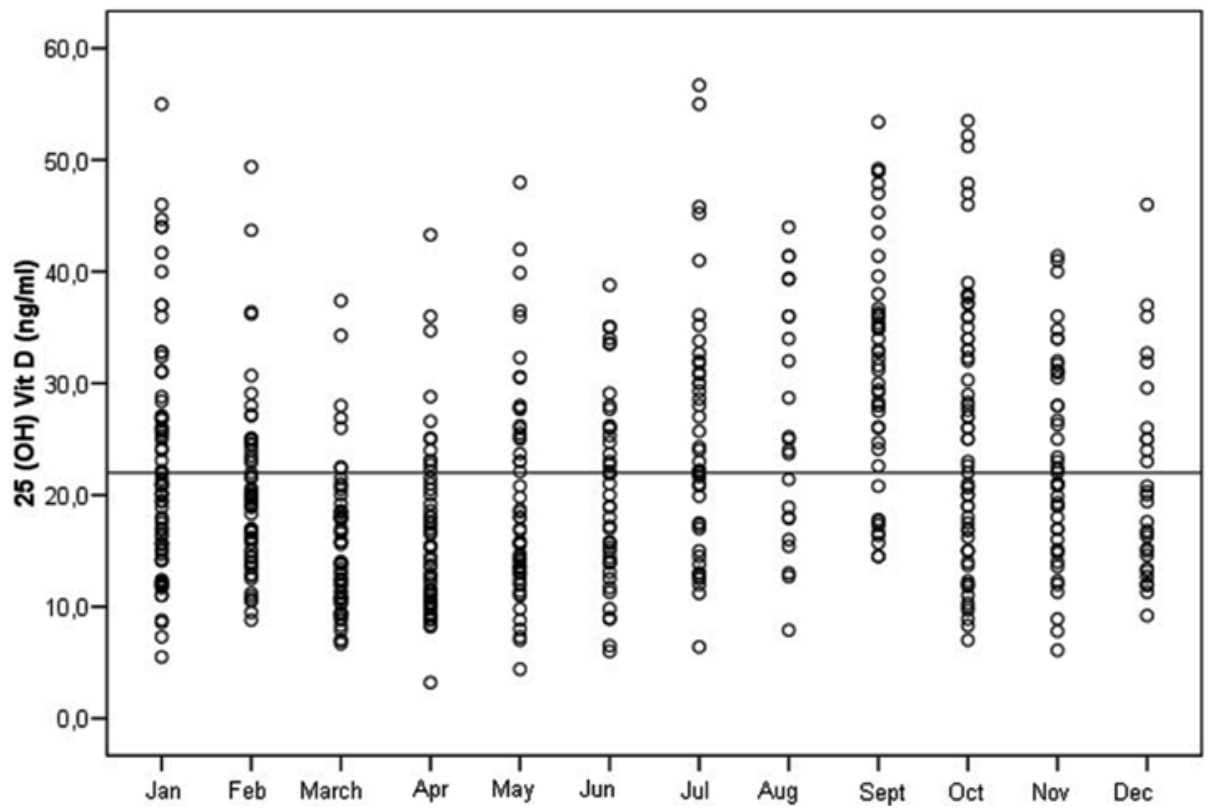

Figure 3. Distribution of serum 25(OH)Vitamin $\mathrm{D}$ values in the studied healthy adults of both sexes during each month of the year. There is considerable fluctuation of the values in the various months (lower during March-May, higher during July-October). Values below the estimated lower normal level (22ng/ml, horizontal line) were detected in $361 / 625$ subjects $(57.7 \%)$ during the whole year. To convert $25(\mathrm{OH})$ Vitamin D values to SI units multiply by 2.5 .

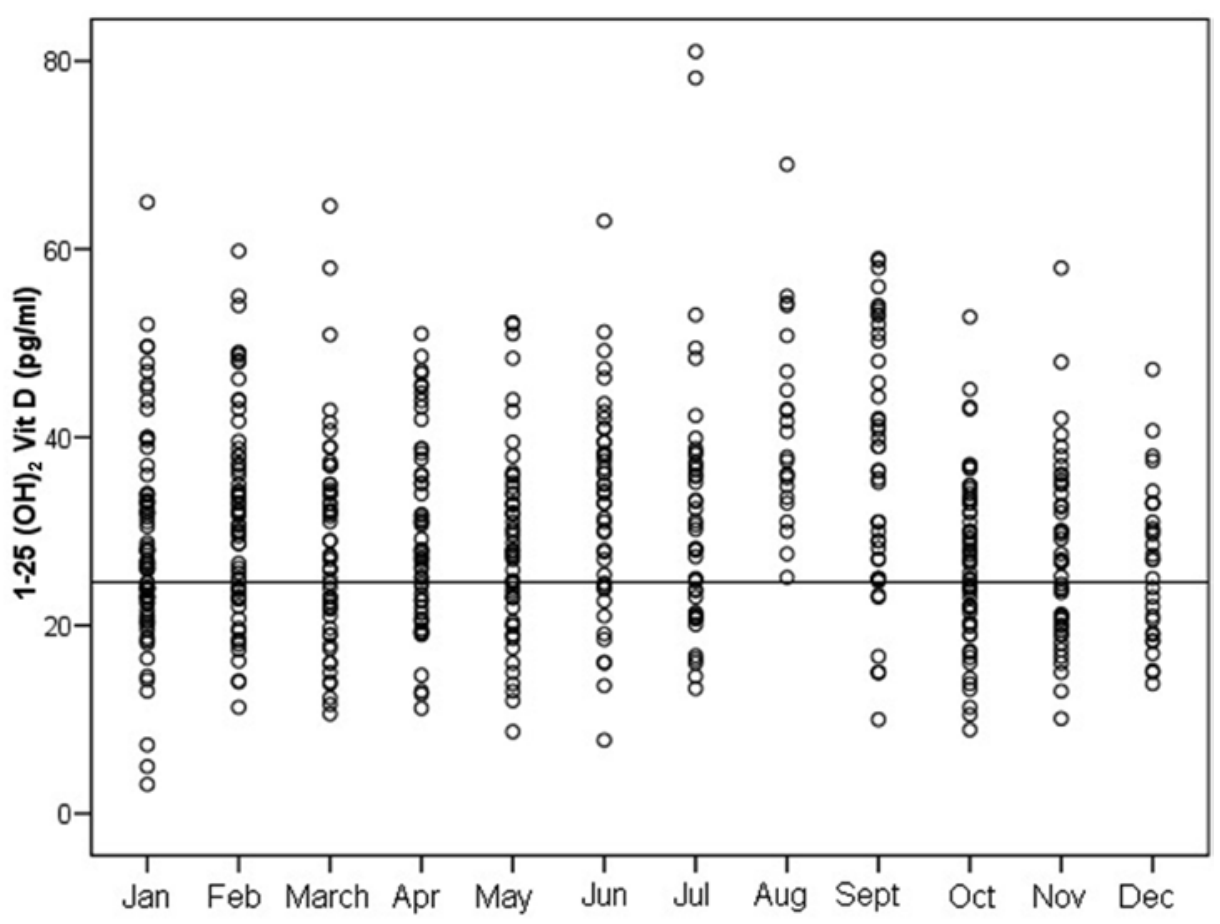

Figure 4. Distribution of serum 1-25(OH $)_{2}$ Vitamin D values in the studied subjects of both sexes during each month of the year. Considerable fluctuation of the values is observed in the various months. Values below the lower normal level $(24.6 \mathrm{pg} / \mathrm{ml}$ estimated by the vitamin D loading test, horizontal line) were detected in 209/625 subjects (33.3\%) during the whole year. Normal values (higher than the lower normal level) in all the studied subjects were found only during August.

To convert 1-25(OH $)_{2}$ Vitamin D values to SI units, multiply by 2.4 . 


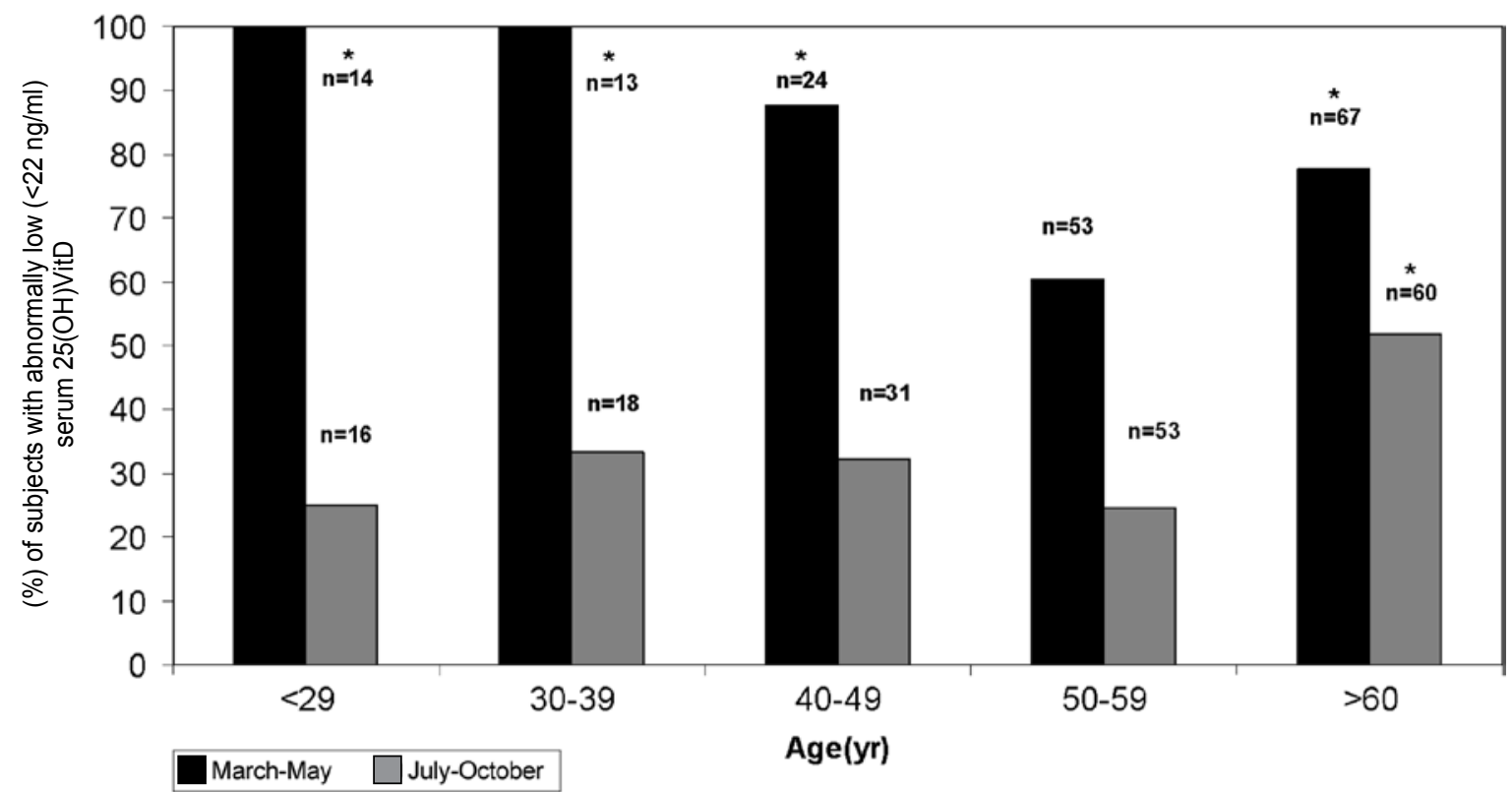

Figure 5. Percentage of subjects with abnormally low serum $25(\mathrm{OH})$ Vitamin D values $(<22 \mathrm{ng} / \mathrm{ml})$ observed in the five age groups during the periods of lower (March-May) and higher (July-October) values ( $n=$ number of subjects in each age subgroup at each period). Statistically significant $(*)$ higher percentage of abnormally low values were observed in the period March-May in the age groups $<29 \mathrm{yr}, 30-39,40-49$ and $>60$ compared to $50-59 \mathrm{yr}(\mathrm{p}=0.004,0.05,0.02,0.05$, respectively $)$ and in the period July-October only in the age group $>60$ compared to $50-59 \mathrm{yr}(\mathrm{p}=0.003)$.

To convert 25(OH)Vitamin D values to SI units, multiply by 2.5 .

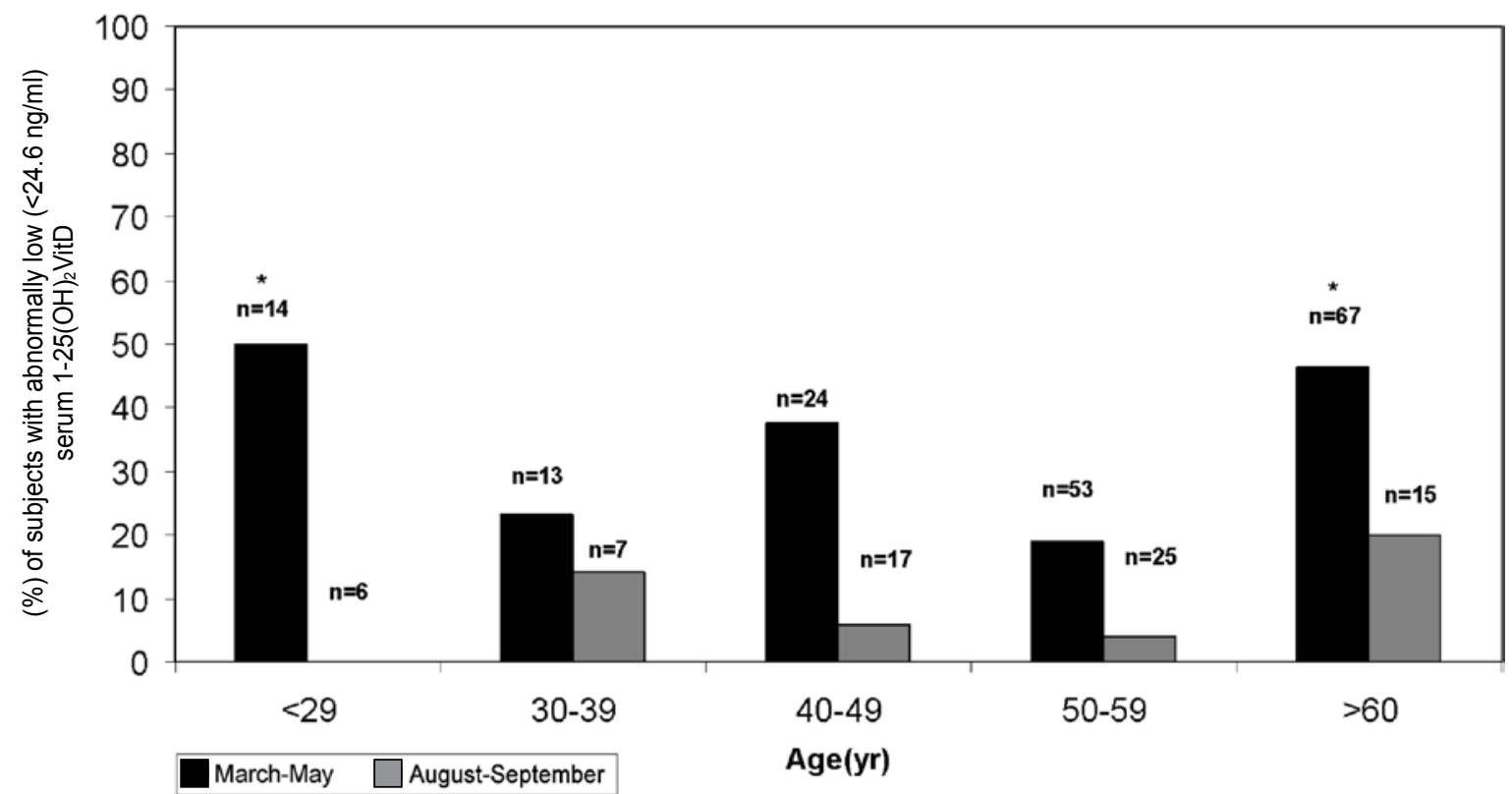

Figure 6. Percentage of subjects with abnormally low serum $1-25(\mathrm{OH})_{2}$ Vitamin $\mathrm{D}$ values $(<24.6 \mathrm{ng} / \mathrm{ml})$ observed in the five age groups during the periods of lower (March-May) and higher (August-September) values ( $n=$ number of total subjects in each subgroup at each period). Statistically significant $\left(^{*}\right)$ higher percentage of abnormally low values was observed in the period March-May for the age group $<29 \mathrm{yr}$ compared to $50-59(\mathrm{p}=0.017)$ and of $>60$ compared to 50-59 $(\mathrm{p}=0.002)$. No statistically significant difference was observed in the period August-September between the five age groups.

To convert $1-25(\mathrm{OH})_{2}$ Vitamin D values to SI units, multiply by 2.4 . 

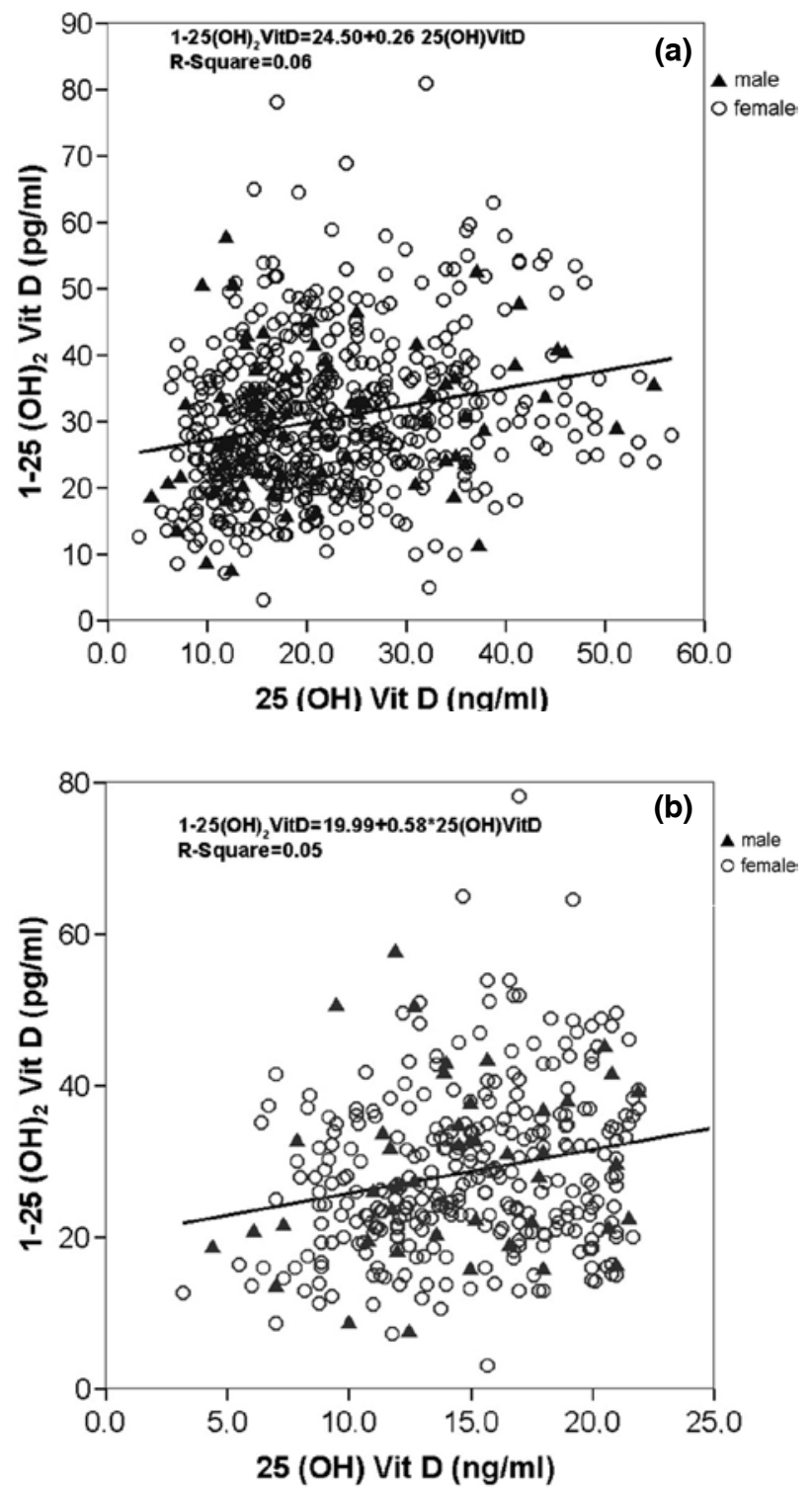

Figure 7. Correlation between serum 25(OH)Vitamin D and $1-25(\mathrm{OH})_{2}$ Vitamin D in all studied subjects (a) and in those with abnormally low $(<22 \mathrm{ng} / \mathrm{ml})$ vitamin D values (b). Highly significant $(\mathrm{p}<0.001)$ positive linear correlation $(\mathrm{r}=0.24)$ between the 2 vitamin $\mathrm{D}$ metabolites in all studied subjects $(\mathrm{n}=614)(\mathrm{a})$, as well as only in those $(\mathrm{p}<0.001, \mathrm{r}=0.22, \mathrm{n}=354)$ with low $(<22 \mathrm{ng} / \mathrm{ml})$ serum $25(\mathrm{OH})$ Vitamin D values $(\mathrm{b})$. To convert to SI units, multiply by 2.5 for $25(\mathrm{OH})$ Vitamin D and 2.4 for $1-25(\mathrm{OH})_{2}$ Vitamin D.

The percentage in the group $>60 \mathrm{yr}$ was significantly higher $(\mathrm{p}<0.003)$ than that corresponding to the age group 50-59 (Figure 5).

The percentage of abnormally low $1-25(\mathrm{OH})_{2}$ Vitamin D values (Figure 6) in the period of lower values (March-May) was significantly lower, fluctuating between $18.9 \%$ (age group 50-59, $\mathrm{n}=53$ ) and $50 \%$ (age group $<29, \mathrm{n}=14$ ) with significantly higher percentages at the age groups of $<29 \mathrm{yr}(50 \%)$ and $>60 \mathrm{yr} n=67(46.3 \%)$ compared to $50-59(18.9 \%)$ $(\mathrm{p}=0.02$ and $<0.002$, respectively). In the period of higher values (August-September) the corresponding percentages fluctuated between $0 \%$ (age group $<29$, $\mathrm{n}=6$ ) and $20 \%$ (age group $>60, \mathrm{n}=15$ ) but without any statistical significance between the five age groups.

A highly significant positive linear correlation $(\mathrm{r}=0.24, \mathrm{p}<0.001)$ was found between serum $25(\mathrm{OH})$ Vitamin D values and those of $1-25(\mathrm{OH})_{2}$ Vitamin $\mathrm{D}$ in the whole group (Figure 7a). The correlation remained unchanged when other statistical methods were used such as the LOWESS, the semi-log or the $\log -\log$ values (data not shown in graphics). If solely the subjects with abnormally low 25(OH)Vitamin $\mathrm{D}$ values $(<22 \mathrm{ng} / \mathrm{ml}, 55 \mathrm{nmol} / \mathrm{L})$ were considered (Figure $7 \mathrm{~b}$ ), the correlation between the two vitamin D metabolites remained $(r=0.22, p<0.001)$. In addition the correlation between $25(\mathrm{OH})$ Vitamin $\mathrm{D}$ and $1-25(\mathrm{OH})_{2}$ Vitamin $\mathrm{D}$ remained when the women without $(\mathrm{r}=0.196, \mathrm{p}<0.001, \mathrm{n}=341)$ or with osteoporosis + osteopenia - OP+OPenia $-(\mathrm{r}=0.315$, $\mathrm{p}<0.001)$ were considered separately.

The highly significant $(\mathrm{p}<0.001)$ negative linear correlation between intact PTH and $25(\mathrm{OH})$ Vitamin $D$ concentration detected in the whole group $(\mathrm{r}=$ 0.29 ), (Figure 2a) persisted when the women without $(\mathrm{r}=-0.254, \mathrm{n}=341)$ or with $\mathrm{OP}+$ OPenia $(\mathrm{r}=-0.579)$ were considered separately.

Furthermore, multivariance regression analysis between intact PTH and 25(OH)Vitamin D and total calcium in the whole group showed that $\mathrm{PTH}$ is significantly correlated with $25(\mathrm{OH})$ Vitamin D. Specifically, there was a negative correlation of PTH with 25(OH)Vitamin D but a non-significant correlation with serum $\mathrm{Ca}$. Both variables account for $7.9 \%$ of the total variation of intact PTH levels (adjusted $\mathrm{R}$ square $=0.076$ ). When instead of total calcium, ionized calcium was calculated the relationship did not change. In this case, both variables accounted for $7.6 \%$ of the total variation in intact PTH levels.

On multivariance regression analysis, when the women without or with $\mathrm{OP}+\mathrm{OPenia}$ were considered 
separately, the significant correlation of intact PTH with 25(OH)Vitamin D and not with calcium (total or ionized) remained. In women without $\mathrm{OP}+\mathrm{OPenia}$, the negative correlation of PTH with $25(\mathrm{OH})$ Vitamin $\mathrm{D}$ and the non-significant with total calcium also remained. Both variables accounted for $6.5 \%$ (adjusted $\mathrm{R}$ square $=0.065)$ of the total variation of intact $\mathrm{PTH}$ levels. Additionally, in women with OP+OPenia the negative correlation of PTH with $25(\mathrm{OH})$ Vitamin D and the non-significant one with total calcium was also observed. In this case, both variables accounted for $15.2 \%$ (adjusted R square $=0.152$ ) of the total variation in intact PTH levels.

When multivariance regression analysis was carried out between intact PTH and 1-25(OH $)_{2}$ Vitamin D and calcium no significant correlation was observed.

\section{DISCUSSION}

Although vitamin D deficiency is generally reported to be very common nowadays, even in developed countries, its exact incidence in apparently normal subjects residing in different countries and or geographical regions is controversial, primarily because there is no consensus on the optimal serum levels of 25(OH)Vitamin D. ${ }^{1-7,9}$

It should be emphasized that, as a rule, the normal serum levels of 25(OH)Vitamin D have been calculated from samples obtained from groups of normal adult volunteers among which an unknown number of subjects with vitamin D insufficiency or even deficiency may be included. ${ }^{1-9}$ Therefore, the soestimated "normal" values evidently do not represent the true normal values. ${ }^{1,5-9}$

Certainly, the distinction between vitamin D sufficient and deficient subjects is not an easy task because most vitamin $\mathrm{D}$ deficient subjects present a slight to moderate vitamin D deficiency and have no characteristic symptoms or signs..$^{1-5}$ With regard to this issue, two approaches could be used to eliminate the uncertainty. The first is based on the assumption that vitamin $\mathrm{D}$ insufficiency begins at the levels of serum 25(OH)Vitamin D below which plasma PTH starts to rise. ${ }^{1,2,6,7}$ In other words, the serum level of 25(OH)Vitamin D needed to maximally suppress plasma PTH concentration is considered as the lower normal level of this vitamin D metabolite. ${ }^{1,2,6,7}$ This could be estimated by two methods. The most simple method is to examine, at baseline, the distribution of $\mathrm{PTH}$ values in relation to $25(\mathrm{OH})$ Vitamin D values in a significant number of normal adults to the point at which plasma PTH values reach a stable plateau level (if ever); the corresponding lower serum $25(\mathrm{OH})$ Vitamin D value at this point is then considered as the lower normal level of this vitamin D metabolite. . $^{1,2,4,6}$ Such studies have indicated that the lower normal values of 25(OH)Vitamin D are between 20-40 ng/ $\mathrm{ml}(50-100 \mathrm{nmol} / \mathrm{L}){ }^{1,2,4,6-9}$

In our study, the negative linear correlation between plasma intact PTH and serum 25(OH)Vitamin $D$ values did not confirm the previously reported PTH plateau values of some studies. . $^{1,2,4,6}$ Indeed, when we used the LOWESS plot, the plasma intact PTH values approximately attained the theoretical plateau in the regression line to be between 22 and $32 \mathrm{ng} / \mathrm{ml}(55$ and $80 \mathrm{nmol} / \mathrm{L})$ of serum $25(\mathrm{OH})$ Vitamin $\mathrm{D}$ concentrations. Therefore, the point at which the plateau of plasma PTH concentration starts should be considered as the lower normal value of serum $25(\mathrm{OH})$ Vitamin D $(22 \mathrm{ng} / \mathrm{ml}, 55 \mathrm{nmol} / \mathrm{L})$. Nevertheless, even with the LOWESS plot, this plateau and the point at which it starts were not clear.

Most likely, the best method is to use a vitamin D loading test, ${ }^{7}$ as we did in the present study. Specifically, $7000 \mathrm{IU}$ of vitamin $\mathrm{D}_{2}$ plus $1 \mathrm{~g}$ calcium were administered orally every day for eight weeks in a group of normal adults. The subjects who did not significantly change their plasma $\mathrm{PTH}$ values during the test were considered as vitamin D sufficient. ${ }^{2,6,9}$ Therefore, in these subjects the lower preloading value of serum $25(\mathrm{OH})$ Vitamin D $(22 \mathrm{ng} / \mathrm{ml}, 55 \mathrm{nmol} / \mathrm{L}$ in our study) was considered as the lower normal value for this vitamin $\mathrm{D}$ metabolite. We also considered as lower normal value of serum $1-25(\mathrm{OH})_{2}$ Vitamin D the one $(24.6 \mathrm{pg} / \mathrm{ml}, 59 \mathrm{pmol} / \mathrm{L})$, corresponding to the serum 25(OH)Vitamin D lower normal value. To our knowledge, such an estimation of $1-25(\mathrm{OH})_{2}$ Vitamin $\mathrm{D}$ lower value by using the vitamin $\mathrm{D}$ loading test has not been previously reported. It must be underlined however that the so-defined lower normal value of serum $1-25(\mathrm{OH})_{2}$ Vitamin D should be considered as suggestive, in view of the uncertainties in the determination of this vitamin $\mathrm{D}$ metabolite. ${ }^{1-3}$

As far as we know, there is only one previous report 
on the use of a Vitamin D loading test for defining normal 25(OH)Vitamin D values. ${ }^{7}$ The authors of that study concluded that the serum $25(\mathrm{OH})$ Vitamin $\mathrm{D}$ value of $20 \mathrm{ng} / \mathrm{ml}(50 \mathrm{nmol} / \mathrm{L})$ should be considered as the minimum value for vitamin D sufficiency. It should be mentioned that their study group included much older subjects (mean age 65 vs $42 \mathrm{yr}$ in our study). ${ }^{7}$ The serum $1-25(\mathrm{OH})_{2}$ Vitamin D was not measured in their study. Despite the age difference in the two studies the minimum value for vitamin $\mathrm{D}$ deficiency definition is quite close, namely $20 \mathrm{vs}$ $22 \mathrm{ng} / \mathrm{ml}$ in our study.

Both studies used almost the same amount of vitamin $\mathrm{D}_{2}$ (7000 IU daily in our study vs $50000 \mathrm{IU}$ once weekly) for the same period ( 8 weeks) and the measuring method was the same for $25(\mathrm{OH})$ Vitamin D (RIA).

The other approach for the estimation of the lower normal level of $25(\mathrm{OH})$ Vitamin D in serum is that proposed by Heaney et al. ${ }^{8}$ This is based on the assumption that the maximum intestinal calcium absorption (65\%) is physiologically necessary for the body to overcome instabilities in calcium intake from food, a condition that could be achieved when serum $25(\mathrm{OH})$ Vitamin D levels are at least $32 \mathrm{ng} / \mathrm{ml}$ $(80 \mathrm{nmol} / \mathrm{L})$. Therefore, according to this criterion this value should be taken as the lower normal level of $25(\mathrm{OH})$ Vitamin D in serum. ${ }^{1,8}$

In our study, the application of a vitamin D loading test for the estimation of the lower normal levels of serum $25(\mathrm{OH})$ Vitamin D was considered more appropriate and more reliable. Furthermore, the so-estimated lower normal level of serum $25(\mathrm{OH})$ Vitamin D $(22 \mathrm{ng} / \mathrm{ml}, 55 \mathrm{nmol} / \mathrm{L})$ is comparable to the lower normal limits (20-30ng/ml, 50-75nmol/L) today accepted by most authorities. ${ }^{1-4,6}$ Also, it is interesting that in our study, the estimated lower normal value for serum $25(\mathrm{OH})$ Vitamin D concentration (22ng/ $\mathrm{ml}, 55 \mathrm{nmol} / \mathrm{L}$ ) was comparable to that derived by correlating plasma intact PTH with serum $25(\mathrm{OH})$ Vitamin D concentrations, using the LOWESS plot.

Considering a value of $25(\mathrm{OH})$ Vitamin D lower than $22 \mathrm{ng} / \mathrm{ml}(55 \mathrm{nmol} / \mathrm{L})$, the percentage of abnormally low serum $25(\mathrm{OH})$ Vitamin values in our group, is unexpectedly high $(57.7 \%)$ for a region with a temperate climate and at a relatively low northern latitude $\left(38^{\circ}\right)$. This finding could be explained by inadequate sunlight exposure, considering that in temperate climate most vitamin $\mathrm{D}$ is produced in the skin via the action of sun light. ${ }^{1,2,10}$ In fact, our subjects (students, housewives, indoor employees, officers) were, according to the information obtained, indoors during most of the year and avoided sunlight exposure during the summer for the risk of skin cancer. In addition, almost all people use commercial sunscreens to protect themselves from UVB radiation. It is well know that sunscreen with a sun protection factor (SPF) of 15 reduces the peripheral conversion of vitamin D by up to 26 times or nearly $99 \% .^{11,12}$ Another significant contributing factor could be the air pollution in the area of Athens that significantly inhibits UVB photons from reaching the earth's surface. Therefore, the net result is limited sunlight action on the skin and decreased vitamin $\mathrm{D}$ production.

These factors could easily explain the even higher percentage of low 25(OH)Vitamin D values at the lower values period (March-May) and the considerably lower percentages at the higher values period (July-October).

Our findings are in accordance with other reports, that even in the sunniest areas, such as Saudi Arabia, United Arab Emirates, Turkey, India, vitamin D deficiency is common ( $\sim 50 \%$ of children and adults), most likely because the skin is shielded from the sun, mainly because of religious reasons. ${ }^{1,13-16}$

It should be mentioned, that there are two previous studies reporting data from our region. ${ }^{17,18} \mathrm{In}$ one of these (the SENECA study), ${ }^{17}$ the population examined included 109 (48 males and 61 females) free living, aged ( $\sim 80 \mathrm{yr})$ subjects from three rural regions of the sunniest in Greece (the Athens environs and the island of Crete). During winter they observed a very high proportion of abnormally low serum $25(\mathrm{OH})$ Vitamin D values $(<15 \mathrm{ng} / \mathrm{ml}, 37.5 \mathrm{nmol} / \mathrm{L}$ ) (about $80 \%$ in women and $50-70 \%$ in men). Certainly, if the lower normal value of $22 \mathrm{ng} / \mathrm{ml}(55 \mathrm{nmol} / \mathrm{L})$ had been used, the percentages of vitamin D deficient subjects would be much higher. The only plausible explanation for the high prevalence of vitamin D deficiency in these subjects (peasants and farmers) is that they cover the whole body with clothes, except for the face and hands when outdoors, even during summer. In 
the second study ${ }^{18}$ that included 279 elderly subjects (231 women and 48 men, median age 71 and $72 \mathrm{yr}$, respectively) living in the same area as the subjects of our study, only $6.5 \%$ could be considered as vitamin D sufficient $[25(\mathrm{OH})$ Vitamin D $>80 \mathrm{nmol} / \mathrm{L}]$ during winter and $35.2 \%$ during the summer. It should also be stressed that compared to our study, there was considerable difference in the time periods and their duration of the lower and the higher values, respectively (Winter: February 15 - March 15, Summer: August 15 - September 15).

In a study by Thomas et $\mathrm{al}^{4}$ conducted in Boston, USA, a subgroup of 77 younger patients (mean age \pm sd: $44 \pm 12 \mathrm{yr}$ ) were evaluated. It was found that vitamin D deficiency was present in $42 \%$ of the patients using a lower threshold for $25(\mathrm{OH})$ Vitamin $\mathrm{D}$ and without reference to the season.

It should be underlined that, despite the high percentage of $25(\mathrm{OH})$ Vitamin D deficiency in our study, only $6 / 64(9.4 \%)$ of the subjects presented low $1-25(\mathrm{OH})_{2}$ Vitamin $\mathrm{D}$ values during the period of higher values (August - September). Furthermore, the $1-25(\mathrm{OH})_{2}$ Vitamin D mean value in March-May (period of lower values) was higher than the lower normal value. These findings are in agreement with previous reports stating that in mild $25(\mathrm{OH})$ Vitamin D deficiency the $1-25(\mathrm{OH})_{2}$ Vitamin $\mathrm{D}$ concentrations is normal or even increased..$^{1-3}$ This is further supported by the finding that about $5 \%$ of our subjects presented values at high-normal levels $(>50 \mathrm{pg} / \mathrm{ml}$, $120 \mathrm{pmol} / \mathrm{L})$.

As to the age groups and periods of lower and higher values, it is very interesting that during MarchMay abnormally low serum 25(OH)Vitamin D values have been observed in all the younger subjects $(<39$ yr), but to a lesser degree in the middle age groups and even the older ( $>60 \mathrm{yr})$. The most plausible explanation for the groups of younger subjects seems to be very low sunlight exposure with consequent vitamin $\mathrm{D}$ deficiency, especially during winter. This is further supported by the observation that during July-October the percentage of abnormally low serum $25(\mathrm{OH})$ Vitamin D values of the young $(<29 \mathrm{yr})$ decreased to, or even fell lower than, those of the other middle age groups, obviously due to increased physical activity outside the city and, consequently, more sunlight exposure during this period of the year. However, even during July-October about $25 \%$ of the young subjects remain vitamin D deficient as do the other middle age groups. Similar results have been reported by Tangpricha et $\mathrm{al}^{19}$ in free living young adults in Boston.

Considerable divergences of the vitamin D reserve during the year (seasonal variation) have also been reported in several studies, although the time periods differed depending on the latitude and regional climatic peculiarities. ${ }^{19-22}$ Furthermore, as far as we know, the influence of age by stratification of the subjects into small age groups as carried out in our cohort has not been studied in detail, especially with regard to seasonal variations. , $^{2,-7,9,11-23}$

Concerning the older group, although during March-May their percentage of abnormally low serum $25(\mathrm{OH})$ Vitamin D values was much lower than that of the younger age groups, they had only a slightly decreased percentage during July-October. As a consequence during this period they presented about double the frequency of abnormally low serum $25(\mathrm{OH})$ Vitamin D values in comparison to the other age groups. This could be explained largely by less exposure to sunlight and also because aging reduces vitamin $\mathrm{D}_{3}$ synthesis (by $75 \%$ in 70 yr-olds). ${ }^{1,2}$ Our results are thus in accordance with the previously expressed view that the aged need more sunlight exposure and/or vitamin D supplementation to be vitamin D sufficient throughout the year. ${ }^{1-3,9,10,17}$

The higher percentage of abnormally low serum $1-25(\mathrm{OH})_{2}$ Vitamin $\mathrm{D}$ values during the period of lower values (March-May) in the groups of young ( $<29 \mathrm{yr}$ ) and older (>60 yr) individuals could be attributed mainly to diminished sunlight exposure. This is further supported by the fact that during the period of higher values (August-September), none of the group aged $<29$ and only $20 \%$ of the group aged $>60 \mathrm{yr}$ presented abnormally low values of this vitamin D metabolite. Furthermore, the better vitamin D status of our middle-aged subjects could be attributed to their more physical activity and way of life in contrast to the young and the aged.

Of special interest is our finding of a positive linear correlation between serum levels of $25(\mathrm{OH})$ Vitamin D and $1-25(\mathrm{OH})_{2}$ Vitamin D. Although such a correlation 
was previously described in some studies, ${ }^{24,25}$ little or no attention was paid to this finding because it was attributed to interferences in the $1-25(\mathrm{OH})_{2}$ Vitamin D assay by the inactive metabolite of $24-25(\mathrm{OH})_{2}$ Vitamin D. ${ }^{24,25}$ Certainly, there is general agreement that the renal production of $1-25(\mathrm{OH})_{2}$ Vitamin $\mathrm{D}$ is regulated by plasma PTH, calcium and phosphorous levels, ${ }^{1-3,11,25}$ and perhaps other novel regulators including FGF 23 and Klotho. ${ }^{26-28}$ Our findings in a large number of adult subjects with a broad spectrum of age and the persistence of the correlation even when only the subjects with abnormally low serum 25(OH)Vitamin D concentrations were considered, and also in women without or with OP+OPenia, strongly suggest that the serum levels of $25(\mathrm{OH})$ Vitamin D possibly play a substantial role in serum $1-25(\mathrm{OH})_{2}$ Vitamin $\mathrm{D}$ production. This is further substantiated by the recent study of Rejnmark et $\mathrm{al}^{29}$ concluding that in postmenopausal women serum $25(\mathrm{OH})$ Vitamin D concentration is the major determinant of serum levels of 1-25(OH $)_{2}$ Vitamin D. ${ }^{29,30}$

Of particular interest is also the finding of a considerable negative linear correlation between $25(\mathrm{OH})$ Vitamin D and Intact PTH concentrations not only in the whole group but also separately in the women without or with OP+OPenia. Such correlations have been previously reported but mainly in postmenopausal women. ${ }^{1-3}$ The presence of the correlation not only in the total group but also in women without or with $\mathrm{OP}+\mathrm{OPenia}$, separately considered, and the fact that in the multivariance analysis the serum calcium (total or ionized) was an insignificant determinant suggests that $25(\mathrm{OH})$ Vitamin D plays a considerable role in the regulation of $\mathrm{PTH}$ secretion.

\section{CONCLUSION}

Our results show that in a representative group of white normal adults living in a temperate climate (northern latitude $38^{\circ}$ ), the frequency of $25(\mathrm{OH})$ Vitamin D deficiency (as estimated by a vitamin D loading test) is unexpectedly high. Furthermore, the correlations between $25(\mathrm{OH})$ Vitamin $\mathrm{D}$ and 1-25(OH $)_{2}$ Vitamin D concentrations and between 25(OH)Vitamin D and Intact PTH in the whole group and also, separately, in the women with or without $\mathrm{OP}+\mathrm{OPenia}$ suggest that $25(\mathrm{OH})$ Vitamin
D most likely constitutes a major determinant not only of $1-25(\mathrm{OH})_{2}$ Vitamin D production but also in the regulation of PTH secretion.

\section{ACKNOWLEDGEMENTS}

We are grateful to Genesis, Ipsen and Leo for their financial support that covered the expenses of statistical analysis, sketches and graphics of this study. We are greatly indebted to Mrs. Katerina Dimitriou for her excellent technical assistance, statistical analysis and elaboration of the manuscript.

\section{REFERENCE}

1. Holick MF, 2007 Vitamin D deficiency. N Engl J Med 357: 266-281.

2. Holick MF, 2006 High prevalence of vitamin D inadequacy and implications for health. Mayo Clin Proc 81: 353-373.

3. Holick MF, Garabedian M 2006 Vitamin D: photobiology, metabolism, mechanism of action and clinical applications. In: Favus MJ, ed. Primer on the metabolic bone diseases and disorders of mineral metabolism. 6th ed. Washington, DC: American Society for Bone and Mineral Research, pp; 129-137.

4. Thomas MK, Lloyd-Jones DM, Thadhani RI, et al, 1998 Hypovitaminosis D in medical inpatients. N Engl J Med 338: 777-783.

5. Lips P, Duong T, Oleksik A, et al, 2001 A global study of vitamin D status and parathyroid function in postmenopausal women with osteoporosis: Baseline data from the multiple outcomes of Raloxifene Evaluation Clinical Trial. J Clin Endocrinol Metab 86: 1212-1221.

6. Chapuy MC, Preziosi P, Maamer M, et al, 1997 Prevalence of vitamin D insufficiency in an adult normal population. Osteoporos Int 7: 439-443.

7. Malabanan A, Veronikis IE, Holick MF, 1998 Redefining vitamin D insufficiency. Lancet 351: 805-806.

8. Heaney RP, Dowell MS, Hale CA, Bendich A, 2003 Calcium absorption varies within the reference range for serum 25-hydroxyvitamin D. J Am Coll Nutr 22: 142-146.

9. Dawson-Hughes B, Heaney RP, Holick MF, Lips P, Meunier PJ, Vieth R, 2005 Estimates of optimal vitamin D status. Osteoporos Int 16: 713-716.

10. Holick MF, 2003 Vitamin D. A millennium perspective. J Cell Biochem 88: 296-307.

11. Sloka S, Stokes J, Randell E, Newhook LA, 2009 Seasonal variation of maternal serum vitamin $D$ in Newfoundland and Labrador. J Obstel Gynaecol Can 31: 313-321.

12. Sayre RM, Dowdy JC, 2007 Darkness at noon, sunscreens and vitamin D3 Photochem Photobiol 83: 459-463.

13. El-Sonbaty MR, Abdul Ghaffar NU, 1996 Vitamin D deficiency in veiled Kuwaiti women. Eur J Clin Nutr 
50: 315-318.

14. Glerup H, Mikkelsen K, Poulsen L, et al, 2000 Commonly recommended daily intake of vitamin $\mathrm{D}$ is not sufficient if sunlight exposure is limited. J Intern Med 247: 260-268.

15. El-Hajj Fuleihan G, Nabusi M, Tamur H, et al, 2001 Hypovitaminosis D in healthy school children. Pediatrics 107: E53.

16. Marwaha RK, Tandom N, Reddy D, et al, 2005 Vitamin $\mathrm{D}$ and bone mineral density status of healthy schoolchildren in northern India. Am J Clin Nutr 82: 477-482.

17. Van Der Wielen RP, Löwik MR, Van Den Berg H, et al, 1995 Serum vitamin D concentrations among elderly people in Europe. Lancet 346: 207-210.

18. Papapetrou PD, Triandaphyllopoulou M, Karga H, et al, 2007 Vitamin D deficiency in the elderly in Athens, Greece. J Bone Miner Metab 25: 198-203.

19. Tangpricha V, Pearce E, Chen J, Holick M, 2002 Vitamin $\mathrm{D}$ insufficiency among free-living healthy young adults. Amer J Med 112: 659-662.

20. Juttmann JR, Visser TJ, Buurman C, de Kam E, Birkenhager JC, 1981 Seasonal fluctuations in serum concentrations of vitamin D metabolites in normal subjects. Brit Med J 282: 1349-1352.

21. Norman A, 1998 Sunlight, season, skin pigmentation, vitamin D and 25-hydroxyvitamin D: integral components of the vitamin D endocrine system. Am J Clin Nutr 67: 1108-1110.

22. Levis S, Gomez A, Jimenez C, et al, 2005 Vitamin D deficiency and seasonal variation in an adult south Florida population. J Clin Endocrinol Metab 90: 1557-1562.
23. Bolland MJ, Grey AB, Ames RW, et al, 2007 The effects of seasonal variation of 25-hydroxyvitamin D and fat mass on a diagnosis of vitamin D sufficiency. Am J Clin Nutr 86: 959-964.

24. Vieth R, Ladak Y, Walfish PG, 2003 Age-related changes in the 25hydroxyvitamin $\mathrm{D}$ versus parathyroid hormone relationship suggest a different reason why older adults require more vitamin D. J Endocrinol Metab 88: 185-191.

25. Devine A, Wilson SG, Dick IM, Prince RL, 2002 Effects of vitamin D metabolites on intestinal calcium absorption and bone turnover in elderly women. Am J Clin Nutr 75: 283-288.

26. Brown EM 2010 Control of PTH secretion In: Parathyroids 2010. From pathophysiology to the clinical use of PTH, Pisa, Febr 11-13, 2010, Abstr Book International Symposium, pp; 2-13.

27. Ichikawa S, Baujat G, Seyahi A, et al, 2010 Clinical variability of familial tumoral calcinosis caused by novel GALNT 3 mutations. Am J Med Genet A 152A: 896-903.

28. Galitzer H, Ben-Dov I, Lavi-Moshayoff V, et al, 2008 Fibroblast growth factor 23 acts on the parathyroid to decrease parathyroid hormone secretion. Curr Opin Nephrol Hypertens 17: 363-367.

29. Rejumark L, Vestergaard P, Heickendorff, Mosekilde L, 2008 Plasma 1-25(OH)2Vitamin D levels decrease in postmenopausal women with hypovitaminosis D. Eur J Endocrinol 158: 571-576.

30. Papapetrou P, 2010 The interrelationship of serum 1-25-dihydroxyvitamin D, 25hydroxyvitamin D and 24,25-dihydroxyvitamin D in pregnancy at term: a meta analysis. Hormones (Athens) 9: 136-144. 